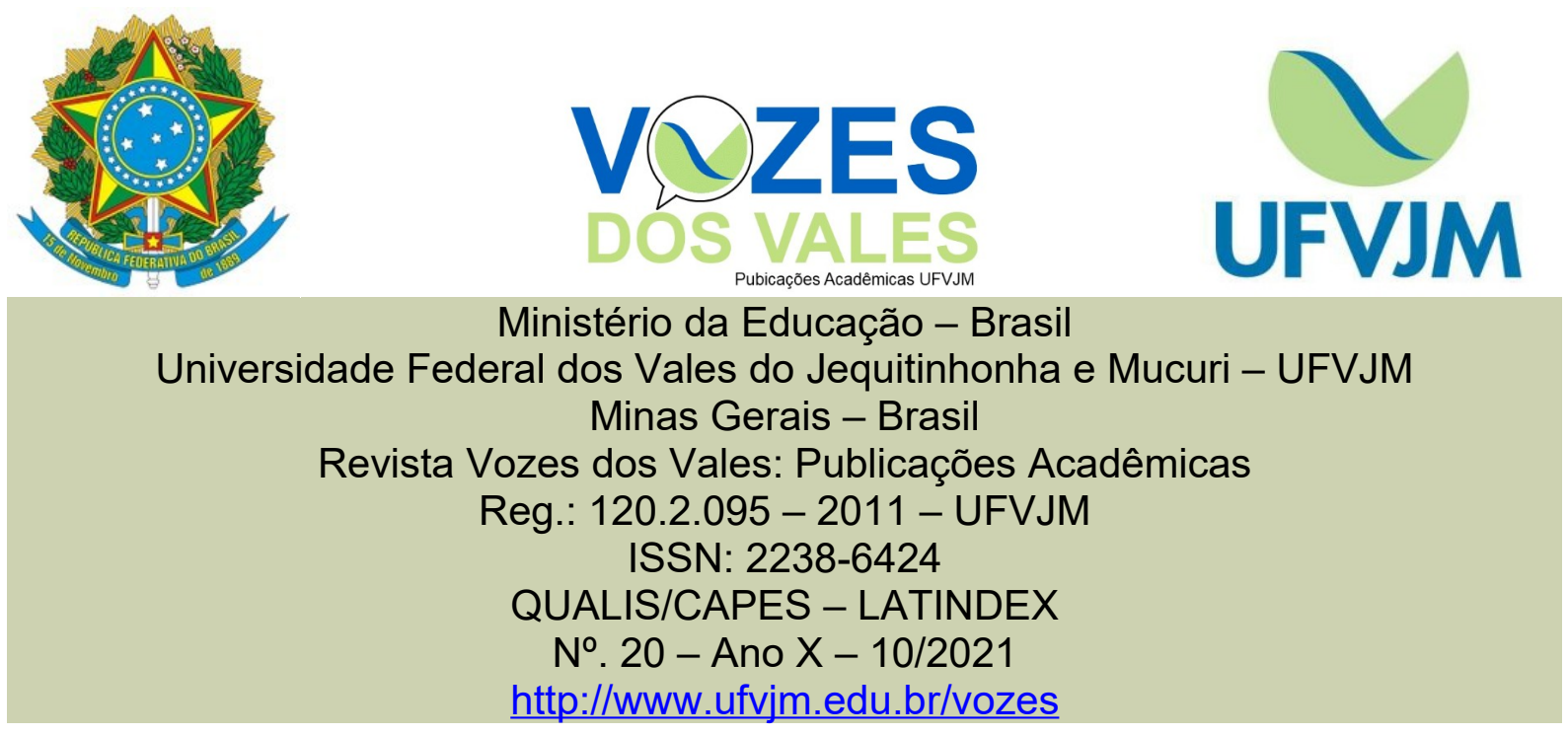

\title{
Dimensão do Suporte na Formação de Professores para o ensino primários em Moçambique: Uma reflexão sobre os saberes docentes vinculados na trajetória histórico curricular
}

\author{
Bonifácio Obadias Langa \\ Mestre em Educação pela Universidade Pedagógica de Maputo - \\ UPM/Maputo - Moçambique \\ Doutorando em Educação: Conhecimento e Inclusão Social na FaE/UFMG \\ Docente da Universidade Pedagógica de Maputo/Moçambique \\ http://lattes.cnpq.br/7635696593299663 \\ E-mail: blanga@ufmg.br \\ Prof. Dr. Júlio Emílio Diniz Pereira \\ Doutor em Educação (Sociologia do Currículo e de Formação de Professores) \\ Professor Titular na Faculdade de Educação da Universidade \\ Federal de Minas Gerais - UFMG \\ http://lattes.cnpq.br/1445205960101729 \\ E-mail: juliodiniz@fae.ufmg.br
}

Resumo: Este artigo buscou refletir sobre as dimensões de suporte nas componentes do mundo dos objetos e das ações na formação de professores a partir das constatações sobre os currículos de formação de professoras/es para o ensino primário em Moçambique no período entre os anos 1975-2018. São analisados os modelos de formação implementados nesse período, correspondentes a três períodos históricos de formação de professores, nomeadamente: período transitório de formaçao de professores (1975-1976); período de consolidação na formação de professores para o sne (1977-1991) e o período de reforma do Sistema Nacional de Educação (SNE) e de reconstituição da rede escolar (1992 a presente data). Analisou-se por meio de estudo documental os suportes institucionais

Revista Vozes dos Vales - UFVJM - MG - Brasil - № 20 - Ano X - 10/2021 Reg.: 120.2.095-2011 - UFVJM - QUALIS/CAPES - LATINDEX - ISSN: 2238-6424 - www.ufvjm.edu.br/vozes 
existentes para a concretização dos objetivos e finalidades curriculares na formação docente para o ensino primário em Moçambique. Os resultados revelam a existência de diversidade de modelos curriculares onde no primeiro período focalizavam mais a questão da formação político-ideológico do professor e pouca relevância dos conteúdos profissionais e acadêmicos. No segundo período, identifica-se uma melhora significativa no campo dos saberes profissionais e acadêmicos porém no último período, abandona-se a incorporação de conteúdos acadêmicos na formação. Em todos esses períodos, registra-se que o nível de ingresso na formação é muito baixo, o que denuncia uma formação precária docente e sem os devidos suportes para fortalecimento da formação inicial, bem como do desenvolvimento profissional docente.

Palavras-chave: Saberes docentes. Formação de professores. Suporte institucional.

\section{Introdução}

A proclamação da independência nacional de Moçambique a 25 de junho de 1975, proporcionou uma viragem no setor da educação, onde o ensino oferecido durante a vigência do colonialismo português, salvo o que era proporcionado nas zonas libertadas ${ }^{1}$ pela frente de libertação de Moçambique $\left(\right.$ FRELIMO $^{2}$ ), era rudimentar e com finalidades civilizatórias de acordo com Golias (1993) e Mazula (1995). Poucos são os que conseguiam ascender aos níveis mais elevados de escolaridade e para o efeito deveria submeter-se no crivo de assimilado ${ }^{3}$. 0 ensino de qualidade destinava-se privilegiadamente para os filhos dos colonos (MAZULA, B.1995, BUENDIA, M. 1999) e a responsabilidade do ensino estava a cargo dos padres católicos ao serviço da colônia, sendo que até 1930 existia apenas uma escola de formação de professores para o ensino indígena - ensino destinados aos nativos.

\footnotetext{
1 À medida que a guerra de libertação nacional foi avançando, foram surgindo territórios fora do controlo da administração portuguesa e sendo ocupados pela FRELIMO. Esses territórios passaram a ser chamados de «zonas libertadas».

${ }^{2}$ Movimento anticolonial que congregando todos os moçambicanos, desencadeou uma luta de libertação nacional a 25 de Junho de 1962, tendo culminado com o alcance do fim da colonização pela assinatura dos acordos de Paz (Lusaka, Zâmbia, 07 de setembro de 1974) que possibilitaram a proclamação a independência nacional a 25 de junho de 1975. Esse movimento, transformou-se em partido popular marxista, tendo passado a constituir governo da República Popular de Moçambique (1975 1990), antes da introdução do sistema multipartidário em 1994. A FRELIMO, governa o país desde 1975 até ao presente momento.
}

\footnotetext{
Assimilado é um estatuto que os indígenas da colónia portuguesa poderiam adquirir e passando a ser considerado portugueses. O processo de assimilação consistiu em europezar os povos dominados, desnaturalizando-os quer pela escola quer através de outros meios de difusão e propaganda do seu aparelho ideológico. Para adquirir-se o estatuto de assimilado "civilizado", era necessário requerer a cidadania portuguesa, devendo o requerente possuir o domínio da língua portuguesa e possuir uma estabilidade financeira (GOLIAS, 1993, p. 31).
}

Revista Vozes dos Vales - UFVJM - MG - Brasil - № 20 - Ano X - 10/2021 Reg.: 120.2.095-2011 - UFVJM - QUALIS/CAPES - LATINDEX - ISSN: 2238-6424 - www.ufvjm.edu.br/vozes 
Com os avanços da luta de libertação nacional registraram-se primeiras experiências de escolarização do povo nas zonas libertadas pela FRELIMO e, com a proclamação da independência nacional a educação é nacionalizada e cria-se o Sistema Nacional de Educação (SNE) pelo decreto-lei No 4/83 de 23 de março de 1983. É à luz dessa lei (4/83) que se institucionaliza a formação de professores em Moçambique, formação essa que conheceu várias trajetórias curriculares ao longo dos períodos históricos que demarcam a profissionalização da carreira docente nesse país.

É no percurso dessa trajetória histórica de formação docente que refletimos no presente artigo, sobre os saberes docentes integrados nos conteúdos curriculares de formação exposto através dos objetivos de formação, numa interface com as diretrizes legais que sustentam o SNE, procurando compreender o mundo dos objetos e das ações subjacentes para a materialização dos objetivos de formação. A razão que fundamenta nossa reflexão emana do ecoar de vozes que questionam a qualidade do ensino oferecido no país, tendo em conta o tipo de formação docente existente.

\section{Contextualizando a trajetória de Formação Docente}

No período compreendido entre 1975 e 1983 o sistema de educação moçambicano ainda baseava-se no modelo herdado do colonialismo contudo, com a nacionalização de ensino a jovem nação ora parida inaugura um período de massificação da escolaridade para a grande parte da população, registrando-se um afluxo maciço de alunos às escolas.

O Ministério da Educação e Cultura (MEC, 2011 ), refere que

\footnotetext{
a "explosão escolar" provocada pela nacionalização do ensino, registrouse num momento em que a maioria dos Professores estrangeiros e alguns moçambicanos abandonavam o país e outros tantos saíam do ensino. Era uma situação muito difícil, sem condições para se atender ao crescimento da demanda escolar. A procura de solução deste problema nasceu necessariamente dos imperativos próprios de situação de emergência, sendo contratados como Professores muitas pessoas com baixo nível de ensino (MEC, 2011, p.5).
}

Revista Vozes dos Vales - UFVJM - MG - Brasil - № 20 - Ano X - 10/2021 Reg.: 120.2.095-2011 - UFVJM - QUALIS/CAPES - LATINDEX - ISSN: 2238-6424 - www.ufvjm.edu.br/vozes 
Qualquer que reunisse os requisitos mínimos exigidos para ensinar poderia ser aceite, dando início a um longo período de integração de pessoas em muito dos casos sem qualificações para a docência, sendo apenas indivíduos necessitados por um posto de emprego no Estado, o que precipitou a decadência e precarização da docência e do ensino escolar.

Entende-se aqui como requisitos mínimos nesse período (1975 - 1983) o nível escolar de $4^{a}$ classe concluída (o equivalente a quarta série), conferida pelo sistema colonial de educação para os indígenas. Importa ressaltar que, na altura da independência, Moçambique tinha uma população com uma porcentagem de cerca de noventa porcento (90\%) de analfabetos de acordo com a agência de informação de Moçambique $(\mathrm{AIM})^{4}$, esse fato de analfabetismo massiva, denuncia a vulnerabilidade que de forma grosseira iria afetar vários setores sociais em particular o sistema de educação e isso apontava para a urgência para a formação de professores.

Com a nacionalização da educação, em 1983 Moçambique institui o primeiro Sistema Nacional de Educação (SNE) pelo decreto-lei 4/83 que tinha como objetivos:

- A erradicação do analfabetismo;

- A introdução da escolaridade obrigatória e,

- A formação de quadros para as necessidades do desenvolvimento econômico e social e da investigação científica, tecnológica e cultural. (Bolentim da República: p.1 I série Número $12,3^{\circ}$ suplemento, 1983).

A formação de quadros para os diversos setores de desenvolvimento do país situava-se no top da agenda e com grande destaque para a formação de professores de modo a criar-se e desenvolver-se uma resposta sistêmica para o normal funcionamento do aparelho de Estado.

Reconhecendo-se que o povo moçambicano foi durante cinco séculos escravizados e dominado colonialmente pelos portugueses, assume-se através dos objetivos e finalidades do ensino escolar que era necessário uma ideologia que proporcionasse-Ihe a libertação da sua mente. Eis porquê o Governo da República

\footnotetext{
${ }^{4}$ https://www.ces.uc.pt/emancipa/gen/mozambique.html, acesso em 07/06/2018

Revista Vozes dos Vales - UFVJM - MG - Brasil - № 20 - Ano X - 10/2021 Reg.: 120.2.095-2011 - UFVJM - QUALIS/CAPES - LATINDEX - ISSN: 2238-6424 - www.ufvjm.edu.br/vozes
} 
Popular de Moçambique concebe como objetivo central do SNE a "formação do Homem novo"(MOÇAMBIQUE, BR, 1983, p.14), como um Homem livre do obscurantismo, da superstição e da mentalidade burguesa e colônia, um homem que assume os valores da sociedade socialista, nomeadamente: a unidade nacional, (...) e o engajamento e contribuição ativa com todos os seus conhecimentos, capacidades e energia na construção do socialismo.

Ao colocar-se essa premissa como objetivo supremo do sistema educativo, entende-se que fosse mesmo necessário para usar da escola para o Povo tomar poder (MACHEL, 1979) e proporcionar ao oprimido a enxergar a sua situação de oprimido como afirma Freire (2018)

é preciso que comecem a ver exemplos da vulnerabilidade do opressor para que, em si, vá operando-se convicção oposta à anterior. Enquanto isto não se verifica continuarão abatidos, medroso, esmagados. Até ao momento em que os oprimidos não tomem consciência das razões de seu estado de opressão, "aceitam" fatalistamente a sua exploração (FREIRE, 2018, pp. 7071).

Era preciso realmente que o povo a partir duma educação escolar padronizada aprendesse os passos da liberdade e, para o efeito, a expansão da rede escolar era ponto de ordem mas o impasse como se disse era a inexistência de profissionais para o setor da educação. No entanto, a premente necessidade de cobertura da rede escolar ora aberta fez com que o Ministério da Educação e Cultura (MEC) abrisse vagas para a contratação de um quadro precário de pessoal para responder as necessidades.

MEC (2011.p.4), refere que para além deste tipo de contratação, criou-se, em 1975, 10 Centros de Formação de Professores Primários (CFPP's), um em cada província. O curso ministrado era de 1 ano o ingresso era com o mínimo $4^{\mathrm{a}} / 6^{\mathrm{a}}$ classe ${ }^{5}$ do ensino primário, a ênfase do curso incidia na área didáctico-pedagógica, com elevação do nível de conhecimentos do carácter geral, formação política e ideológica do partido FRELIMO aos candidatos para a docência - uma espécie de lavagem cebral e prémunição dos futuros docentes para disseminarem nas escolas

O Sistema Nacional de Educação moçambicano está estruturado em níveis de ensino (primário, secundário e superior), sendo que os ensinos primário e secundário constituem o ensino geral distribuído em 12 classes ( $1^{\text {a }}$ à $12^{\mathrm{a}}$ classe) equivalentes às séries escolares brasileiras até ao nível médio.

Revista Vozes dos Vales - UFVJM - MG - Brasil - № 20 - Ano X - 10/2021 Reg.: 120.2.095-2011 - UFVJM - QUALIS/CAPES - LATINDEX - ISSN: 2238-6424 - www.ufvjm.edu.br/vozes 
a dogmatização e idolatrização do partido FRELIMO pelos moçambicanos. Todos os Centros de formação, em conjunto formavam cerca de 800 Professores por ano. Os Formadores (Instrutores) dos centros de formação de professores primários (CFPP) foram escolhidos de entre Professores com habilitações do curso de Magistério Primário (de nível Médio) e de Professores de Posto Escolar que foram submetidos a curso de curta duração para aprimorar a sua formação político-pedagógica. Para além destes Centros, foram criados também 4 Centros Reginais de reciclagem que capacitavam cerca de 3.000 Professores do então Ciclo Preparatório para o Ensino Secundário.

Como se pode perceber a partir do excerto acima, a formação acelerada de professores estava voltada com mais ênfase para o desenvolvimento dos métodos e técnicas ensino e o desenvolvimento da ideologia do partido governante do Estado.

Tratando-se de uma nação que era emergente, era preciso para todos setores sociais produtivos de quadros qualificados e, sem dúvidas que era necessário apostar na escolarização de crianças, jovens e adultos de modo a garantir a construção de uma nação próspera. Como destaca o Ministério da Educação e Cultura (MEC, 1999, p. 8), as prioridades identificadas na Política Nacional de Educação (PNE), o enfoque das primeiras secções do documento é sobre a educação básica e a estratégia do Governo para expandir o acesso e melhorar a qualidade nas escolas primárias. Porém, em nenhum momento apontase como prioridade a formação profissional do professor como prioridade, nem se criam incentivos ou atractivos profissionais para que os jovens e adultos se engajem na carreira. Mesmo analisando os problemas fundamentais do sector da educação o professor não aparece neste nível como se pode perceber a partir do MEC (1999)

existem no sistema educativo moçambicano três problemas fundamentais que afetam todos os níveis do sistema e, virtualmente, todas as instituições em cada nível. $O$ primeiro consiste no limitado acesso às oportunidades educativas, o segundo é a baixa qualidade e o terceiro é o custo da expansão do acesso e da melhoria da qualidade (MEC, 1999, p. 9).

Revista Vozes dos Vales - UFVJM - MG - Brasil - № 20 - Ano X - 10/2021 Reg.: 120.2.095-2011 - UFVJM - QUALIS/CAPES - LATINDEX - ISSN: 2238-6424 - www.ufvjm.edu.br/vozes 
A ideia subjacente que se pode ater é de que não há registro de problemas no que tange à docência, seus processos constitutivos, olhando para problemas atuais como nos faz perceber Gatti (2016, p. 163), que as preocupações com a melhor qualificação da formação de professores e com suas condições de exercício profissional não são recentes. Porém, hoje, avolumam-se essas preocupações ante o quadro agudo de desigualdades socioculturais que vivemos e ante os desafios que o futuro próximo parece nos colocar.

$E$, neste aspecto há que considerar na formação profissional docente dentre várias, a dimensão do suporte cultural pois Gatti (2016, p. 163) entende que a formação, não é uma questão que se restringe a técnica, muito menos às tecnologias. Não é uma questão formal. Ela implica perguntar-se por significados históricos na compreensão dos processos educativos, a partir de cortes sincrônicos, considerando os conflitos, as contradições entre os valores locais e os da cultura em geral, ou seja, é preciso inserir-se nos marcos de uma perspectiva cultural. Todavia, em Moçambique houve registro do que apelidamos de "pecado capital" - a não inclusão das línguas autóctones no sistema de educação, desvalorizando-se desse modo o conhecimento cultural e subjugando o povo a um sistema de educação neocolonial e hostilizante por conta do uso do Português no ensino para uma população não proficiente, justificando-se para tanto como língua que garante a unidade nacional, sendo porém uma clara violação de direitos e implantação da elitização do ensino (LOPES, 2009).

É fundamental questionar que qualidade de ensino se pode esperar para um país que mesmo assumindo a problemática de qualidade pouco faz para um dos pilares indispensáveis de suporte do sistema como destaca MEC (PEE, 1999, p. 10): em todos os níveis, os professores não estão qualificados para os postos que ocupam. Aproximadamente um quarto de todos os professores do ensino primário (EP1), não possuem nenhuma formação e a maioria recebeu apenas seis anos de escolarização e um ano de formação profissional. A limitada capacidade de formação inicial de professores representa um sério obstáculo à expansão dos ingressos nas escolas primárias e secundárias e as oportunidades de formação em

Revista Vozes dos Vales - UFVJM - MG - Brasil - № 20 - Ano X - 10/2021 Reg.: 120.2.095-2011 - UFVJM - QUALIS/CAPES - LATINDEX - ISSN: 2238-6424 - www.ufvjm.edu.br/vozes 
exercício continuam sendo limitadas. A capacidade de gestão, a todos os níveis do sistema educativo, desde o Ministério da Educação até a escola, é fraca.

Nesse sentido, entendemos que o Ministério da Educação, no intuito de reverter o atual cenário de fraca qualidade, repensar o currículo de formação, o processo de formação, as condições de trabalho, as motivações profissionais, entre outras dimensões pois, é sobejamente sabido que, nas instituições formadoras, de modo geral, o cenário das condições de formação dos professores não é animador [...] e, quanto às condições de trabalho oferecidas ao professorado, podemos dizer que, na maioria dos casos o salário é relativamente baixo e quase não há perspectivas de se agregar mais valor a ele durante os anos de exercício profissional. A carreira não se mostra compensatória, (Gatti, 2016).

Face ao problema da fraca qualidade, sustenta-se ademais que os pais não querem simplesmente lugares para os seus filhos nas escolas. Eles querem ter a certeza de que, uma vez matriculados na escola, os seus filhos aprendem alguma coisa. Os atuais níveis de procura da escola só serão sustentáveis, se a qualidade da educação melhorar ao longo do tempo (MEC, 1999).

\section{Do Paradigma Colonial Da Formação De Professores Do Ensino Primário Aos Primeiros Anos Da Idependência}

Na província ultramarina de Moçambique - atual República de Moçambique, foi criada em 1930 a primeira escola de formação docente para atender à política de assimilação do indígenas. Segundo Golias (1993)

é a partir de $1930 \mathrm{e}$ particularmente com assinatura dos dois acordos missionários - Concordata e Estatuto missionário em 1940 e 1941 respectivamente que o Governo Português começou a impor uma política rigorosa de educação e assimilação em Moçambique ( GOLIAS, 1993, p. 33).

Para tanto, foi implantada a escola de formação docente para atender ao ensino primário indígena. Com este marco histórico na formação de professores iniciava-se a caminhada para profissionalização docente na então colônia portuguesa - Moçambique.

Revista Vozes dos Vales - UFVJM - MG - Brasil - № 20 - Ano X - 10/2021 Reg.: 120.2.095-2011 - UFVJM - QUALIS/CAPES - LATINDEX - ISSN: 2238-6424 - www.ufvjm.edu.br/vozes 
Alcançada a independência nacional em Moçambique e, com a experiência das zonas libertadas institui-se a formação de professores com objetivos de assegurar a formação integral dos docentes

munindo-os da ideologia científica do proletariado, capacitando-os para assumirem a responsabilidade de educar e formar os jovens e adultos, forjar no professor uma profunda consciência patriótica e revolucionária, baseada nos princípios do partido FRELIMO [....], e permitir ao professor a elevação constante do seu nível de formação político e ideológica, científico técnica e psicopedagógica. (BR, p.19).

De acordo com Ministério da Educação (MINED, 2011),

a necessidade de transformar o sistema de educação colonial, virado para as minorias, numa educação para a maioria e para valores da moçambicanidade implicou a implantação de programas de emergência para a capacitação de Professores (MINED, 2011.p. 8).

As experiências acumuladas nestes processos de "capacitação" possibilitaram o desenvolvimento de modelos de formação que responderam as necessidades da expansão do sistema educativo em diferentes momentos. Para responder ao crescente número de alunos, viu-se a necessidade de se formar um elevado número de Professores, garantindo-lhes apenas uma base mínima de formação profissional, baseada em níveis acadêmicos bastante baixos, como são os casos dos modelos de formação de $6^{\text {a }}$ classe +1 ano, $6^{\text {a }}$ classe +3 anos, $7^{\text {a }}$ classe + 3 anos e $7^{\text {a }}$ classe $+2+1$ ano, entre os anos 1982 a 1983, 1983 a 1991, 1991 a 2007 e 1999 a 2003 respectivamente.

Tendo envista responder às exigências e demandas do Sistema Nacional de Educaçõ (SNE) foram instituidos esses modelos de formação docente objetivandose preparar os futuros professores para que:

i) adquiram conhecimentos sociopolíticos necessários à compreensão e prática da linha política do Partido FRELIMO e, a uma actuação e comportamento próprios de um agente educador; ii) adquiram conhecimentos básicos científicos e técnicos que garantam a melhoria da qualidade de ensino através de conhecimentos psicopedagógicos, didácticos e de formação geral; iii) adquiram conhecimentos psicopedagógicos metodológicos básicos necessários ao desenvolvimento da capacidade de resposta às situações que se apresentam na actividade docente e de estabelecimento de uma relação correcta professor - aluno; iv)

Revista Vozes dos Vales - UFVJM - MG - Brasil - № 20 - Ano X - 10/2021 Reg.: 120.2.095-2011 - UFVJM - QUALIS/CAPES - LATINDEX - ISSN: 2238-6424 - www.ufvjm.edu.br/vozes 
desenvolvam a consciência crítica, a imaginação e criatividade e o espírito de inovação; v). adquiram conhecimentos (...) no sentido de saber o que há a mudar e como, saber inserir a escola na comunidade (MINED, 2011.p. 8)

Com um plano de estudos subdividido em três áreas principais a saber: Sociopolítica; psicopedagógica e formação metodológica, esses modelos de formação docente, pouco proporcionavam conhecimentos de base referidos em Shulman (1987) nomeadamente: Conhecimento sobre objeto do ensino, Conhecimento pedagógico, Conhecimento pedagógico sobre o objeto de ensino, Conhecimento curricular, Conhecimento das características dos aspectos cognitivos e da motivação dos estudantes, Conhecimento do contexto educativo e Conhecimento das finalidades educativas dos valores educativos e dos abjetivos. Não obstante de dar primazia aos estudos ideológicos do partido FRELIMO e preterir os aspetos de base para a docência como os referidos por Shulman, tomava-se o tempo de formação instruindo o formando para perpetuar a hegemonia partidária frelimista dando retorno à situação de opressão. Porém, como refere Freire (2017.p.73) a ação política junto aos oprimidos tem de ser, no fundo, ação cultural para a liberdade, por isso mesmo, ação com eles. Nesse sentido, fazia jus que a preparação docente aprimorasse além dos conhecimentos de base já destacados por Shulman, a componente etnolinguística que na visão de Lopes (2009), configura-se relevante para melhorar a qualidade de ensino-aprendizagem, além de descolonizar cultural e cientificamente aos povos oprimidos, uma vez que a língua portuguesa foi durante longos séculos veículo escravizador e de supremacia racial e cultural, como destaca Golias (1993, p.35) "a língua que nós ensinamos é ou não superior aos dialectos deles" - palavras do chefe do Governo Português Salazar, em 1963.

O processo escolar, na formação docente e no ensino escolar deveria basear-se nas línguas autóctones como sugere Lopes (2009) como mecanismo revolucionário do convencimento das massas oprimidas para que aceitem a luta pela libertação pois eles precisam reconhecer-se como homens (FREIRE, 2017). portanto, esse cenário poderia advir de uma formação profissional docente que atenda às especifidades para o ensino que respeite os valores e hábitos culturais e que por conseguinte os promova e compreendendo as particularidades contextuais

Revista Vozes dos Vales - UFVJM - MG - Brasil - № 20 - Ano X - 10/2021 Reg.: 120.2.095-2011 - UFVJM - QUALIS/CAPES - LATINDEX - ISSN: 2238-6424 - www.ufvjm.edu.br/vozes 
do país, em oposição ao sistema de educação implantado que, desvalorizou e desqualificou os valores e hábitos culturais vinculados nas línguas autóctones, por oferecer um sistema de educação docente somente em português sabendo-se que nessa altura quase a totalidade $(97 \%)$ da população moçambicana não era falante da língua portuguesa. É de destacar que neste período a escolaridade era mesmo obrigatória e com uso de métodos coercivos e agressivos (física e psicológica) típico da pedagogia colonial conforme Golias (1999), pois os alunos, sejam eles crianças ou adultos não eram proficientes em Português. Nesses modelos de formação docente, predominava a racionalidade técnica ${ }^{6}$ e o estágio decorria num período de sessenta dias em escolas primárias circunvizinhas, fragmentado do processo teórico de ensino.

Indagando sobre os pressupostos para o acesso à formação/capacitação e ou à carreira docente baseado nos graus de escolaridade adquiridos no sistema escolar colonial, percebe-se que os candidatos só poderiam possuir entre a $4^{\mathrm{a}}$ classe rudimentar e a $6^{a}$ classe. Ora, esses graus acadêmicos são tão baixos e não garantem pressupostos científicos (conhecimento do conteúdo) para que os futuros professores ofereçam um ensino de qualidade ${ }^{7}$ pelo fato de que o sistema colonial não oferecia um ensino primário de qualidade para os povos indígenas/nativos que não fossem assimilados (GOLIAS, 1993, p.31). Nesta ótica percebe-se aqui a falta de um alicerce de suporte de conhecimentos científicos, ou seja, défice de conhecimento proporcionado pela deficiente formação acadêmica anterior à formação profissional bem como pelo reduzido tempo de preparação, não obstante de não utilizar-se as línguas autóctones nos processos educacionais.

\footnotetext{
$6 \quad$ De acordo com Diniz-Pereira (2014) apud Schön, o modelo de racionalidade técnica, também conhecido como a epistemologia positivista da prática, "a atividade profissional consiste na solução instrumental de um problema feita pela rigorosa aplicação de uma teoria científica ou uma técnica".

Artigo $1^{\circ}:$ «O ensino indígena tem, por fim, conduzir gradualmente o indígena da vida selvagem para a vida civilizada, formar-lhe a consciência de cidadão português e prepará-lo para a luta da vida, tornando-se mais útil à sociedade e a si próprio». Artigo $7^{\circ}:$ «O ensino primário rudimentar destina-se a civilizar e nacionalizar os indígenas das colônias, difundindo entre eles a língua e os costumes portugueses» (MEC/GÊS,1980:p. 24/25) disponível em http://www.macua.org/livros/Aeducacaocolonialde1930a1974.htm

Revista Vozes dos Vales - UFVJM - MG - Brasil - № 20 - Ano X - 10/2021 Reg.: 120.2.095-2011 - UFVJM - QUALIS/CAPES - LATINDEX - ISSN: 2238-6424 - www.ufvjm.edu.br/vozes
} 


\section{Os Saberes Docentes Na Formação De Professores No Primeiro Período Do Sistena Nacional De Educação}

No período compreendido entre 1983 e 1992 a política nacional de educação baseou-se fundamentalmente na expansão da rede escolar para possibilitar que a maioria dos moçambicanos tivessem acesso ao serviços de educação. Todavia, com a guerra civil ${ }^{8}$ que eclodiu momentos após a proclamação da independência, o país assistiu a uma regressão no que tange à expansão da rede escolar e permanência dos alunos no sistema como aponta Brück (1998) que, o capital humano também sofreu erosão, destruição e redirecionamento bem como uma destruição e erosão das escolas primárias a uma taxa média anual de cerca de $6 \%$ para os anos de 1983 a 1991. De um total de cinco mil e oitocentos e oitenta e seis (5.886) escolas existentes em 1893 pelo menos cerca de três mil e quatrocentas e duas (3.402) escolas foram encerradas/destruídas.

Após a constituição do SNE e com a experiência dos primeiros anos de independência, inaugurou-se nesse período um modelo de formação docente designado Modelo de $6^{a}+3$ anos que vigorou de 1983 a 1991 ou $7^{a}+3$ anos de 1991 a 2007.

Até 1983 o Ensino Primário (EP) era de seis classes, tendo passado para sete classes no ano de 1984 com a introdução do Sistema Nacional da Educação. No cômputo geral, o currículo abarcava três objectivos fundamentais em consonância com as disposições legais em BR(1983.p.19), a formação políticoideológica, formação académica e formação profissional (INDE, 1998).

Como se pode depreender, a formação docente assentava sobre Conhecimento sobre o objeto do ensino e sobre o conhecimento pedagógico, em se referindo ás categorias de conhecimento básico para a docência na perspectiva de

\footnotetext{
${ }^{8}$ A guerra civil de Moçambique (guerra dos 16 anos), foi um conflito armado civil que iniciou em 1976, um ano após a fundação da Resistência Nacional Moçambicana (RENAMO) na então Rodésia do Sul, atual República do Zimbabué (antiga colônia britânica) em 1975. A contestação da política comunista da FRELIMO, levou a RENAMO, liderada inicialmente por um dos fundadores, André Matade Matsangaíssa (18 de março de 1950 - 17 de outubro de 1979), morto em um combate, a mover uma guerra de desestabilização generalizada em todo o território nacional. Com a morte do seu comandante (Matsanagaíssa), Afonso Macacho Marceta Dlakama (Mangunde, Sofala, 01 de janeiro de 1953 - Gorongosa, Sofala, 3 de maio de 2018), passou a assumir o comando, até a assinatura dos acordos gerais de paz (AGP) em Roma (Itália) a 4 de outubro de 1992. Do conflito armado resultou que cerca de um milhão de pessoas pereceram devido aos assassinatos e à fome e, mais de cinco milhões de civis foram deslocados e muitos civis sofreram acidentes por minas terrestres e mutilações de órgãos.
}

Revista Vozes dos Vales - UFVJM - MG - Brasil - № 20 - Ano X - 10/2021 Reg.: 120.2.095-2011 - UFVJM - QUALIS/CAPES - LATINDEX - ISSN: 2238-6424 - www.ufvjm.edu.br/vozes 
Shulman (1987) e Nóvoa (1995). Com um total de 21 disciplinas curriculares perfazendo um total de 3.710 horas letivas sendo que cerca de $50,6 \%$ do tempo era destinado para a área de formação profissional, INDE( 1998.p.3).

Note-se aqui a retoma do modelo colonial de formação de professores que não atende aos alicerces do conhecimento científico que julgamos serem basilares para que a aprendizagem sobre outros conhecimentos (didático e psicopedagógico) bem como o exercício da práxis tenham êxitos. Não obstante a ausência desse suporte acadêmico, verificou-se a ausência do suporte vocacional e motivacional para o ingresso e permanência na carreira do magistério, segundo destaca o Ministério da Educação e Cultura (MEC,1995, p.24) que nesse momento, o corpo docente em exercício, nas escolas, apresentava fracas qualificações pedagógicas o que ia levar o Governo a adotar medidas estratégicas, visando superar aquelas lacunas como a baixa motivação dos professores que conduz ao absentismo e ao fraco desempenho o que, por sua vez, reduz o tempo de contato efetivo entre o professor e os alunos, enfraquecendo assim, o processo de ensino-aprendizagem, daí que, o Governo ia concentrar as suas atenções na promoção de medidas para a elevação da motivação do corpo docente.

Entendemos aqui um cenário de ausência de suportes funcionais ou estruturais que possibilitariam a uma formação sólida de professores qualificados e motivados para o exercício da docência.

A primazia de formação profissional (conhecimento didático) que se desenvolveu ao se preterir a formação sobre o conhecimento do objeto de ensino, mostra-se problemática pois estudos realizados denunciam fraqueza em relação ao nível de conhecimento de objeto do ensino pela parte dos professores (GOLIAS,1991; INDE,1995; MARTINS e NHAMPULE, 1997).

Neste sentido, a formação docente poderia, reconhecendo a deficiência de conhecimentos científicos dos candidatos ao magistério, derivada de baixo nível de escolaridade e fraqueza do ensino-aprendizagem, ampliar o campo de estudos sobre o conhecimento do objeto de ensino de forma a elevar o nível de sua compreensão, para municiar os professores sobre as habilidades profissionais e

Revista Vozes dos Vales - UFVJM - MG - Brasil - № 20 - Ano X - 10/2021 Reg.: 120.2.095-2011 - UFVJM - QUALIS/CAPES - LATINDEX - ISSN: 2238-6424 - www.ufvjm.edu.br/vozes 
acadêmicas (HOROWITZ, DARLING-HAMMOND e BRANSFORD, 2019). Fica portanto, evidente que a baixa qualificação acadêmica, associada aos baixos investimentos na formação docente prejudicarão o futuro professor, assim como o seu desenvolvimento profissional uma vez que lecionará sobre um objeto desconhecido. Embora Freire (2017.p,90) seja de opinião de que isto não significa, porém, que a opção e a prática democrática do professor ou da professora sejam determinadas por sua competência científica, acreditamos que uma vez que o nível de conhecimentos científicos dos candidatos por ser demasiado baixo, eles precisam de um aprofundamento fundamentalmente sobre o conhecimento do objeto de ensino.

Embora existam programas de formação contínua para professores em exercícios (MINED, 2012), com a finalidade de proporcionar um desenvolvimento profissional aos professores, sucede que esses programas de formação contínua estão muito distante das necessidades profissionais docente e são como um adendo na maioria das vezes da formação que faltou e, nesse apanágio, Franco (2019, p. 99) aconselha que, a formação contínua não deve ser encarada como um adendo à formação que faltou. Formação contínua não é suprir deficiência de formação anterior, formação contínua é a necessidade de integrar vida e formação; articular a pessoa do professor às circunstâncias de seu trabalho e profissão, de forma crítica e integrada; criando condições de vivências formativas que permitem o autoconhecimento; a autoformação; os processos de identidade e profissionalização docente.

Nesse sentido, pode-se afirmar que com esse modelo de formação docente, associado à baixa qualificação dos seus candidatos, pouco se duvida que o desempenho dos egressos será igualmente baixo, o que poderá ocasionar desníveis de desempenho do aluno tendo em conta a falta de um preparo profissional adequado do professor que sirva-lhe de alicerce para o enfrentamento dos dilemas da aprendizagem dos alunos e por conseguinte, ajudar as crianças a resolverem problemas básicos de aritmética entre outros de domínio científico como refere Golias (1993), ao destacar a baixa qualidade de professores.

Revista Vozes dos Vales - UFVJM - MG - Brasil - № 20 - Ano X - 10/2021 Reg.: 120.2.095-2011 - UFVJM - QUALIS/CAPES - LATINDEX - ISSN: 2238-6424 - www.ufvjm.edu.br/vozes 
Não obstante o programa curricular privilegiar a formação sobre o conhecimento pedagógico que é atribuído o condão de espinha dorsal INDE (1998.p, 10), dá mais relevância ao clássico de racionalidade técnica em que o estágio encontra-se isolado da componente curricular teórica, criando uma desconexão entre a teoria e a prática.

O futuro professor pela sua deficiência dos saberes profissionais poderá participar do movimento de reprodução das desigualdades sociais (BORDIEU e PASSERON, 1975), pelo fato de que a qualidade do ensino que será ofertado pela escola com este tipo de professores em nada ajudará aos desfavorecidos "oprimidos" e desprovidos de conhecimentos que fazem parte dos cerca de oito milhões de pessoas que não sabem ler, escrever e fazer cálculo dos quais cinco milhões são adolescentes e jovens dos 15 aos 19 anos de idade, e outros três milhões são idosos, principalmente mulheres, conforme aponta a Agência de Informação de Moçambique (AIM) em sua publicação do dia 08.09.2016 disponível em http://www.dw.com/pt.

Parafraseando Arroyo (2017, p.18), precisamos de mestres para desempenho dum "ofício" de qualidade profissional, sabendo que os ofícios se referem a um coletivo de trabalhadores qualificados, os mestres de um ofício que só eles sabem fazer, que Ihes pertence, porque aprenderam seus segredos, seus saberes e suas artes. Uma identidade respeitada, reconhecida socialmente, de traços bem definidos.

\section{A Reforma do Sistema Nacional de Educação e a (re) - construção de saberes docentes na Formação de Professores Para o Ensino Primário}

A revisão da Constituição da República em 1990, desencadeou a ocorrência de vários acontecimentos históricos para Moçambique, a destacar a assinatura dos acordos gerais da Paz a 4 de outubro de 1992 entre o Governo de Moçambique e a Resistência Nacional Moçambicana (RENAMO), pondo fim a uma guerra civil que durou cerca de 16 anos, além de se ter efetivado a primeira reforma do SNE em 1992, através da lei 6/92 de 6 de Maio e concomitantemente a reforma dos currículos escolar e de formação docente.

Revista Vozes dos Vales - UFVJM - MG - Brasil - № 20 - Ano X - 10/2021 Reg.: 120.2.095-2011 - UFVJM - QUALIS/CAPES - LATINDEX - ISSN: 2238-6424 - www.ufvjm.edu.br/vozes 
A política nacional de educação nesse período pretendia, assegurar o acesso à educação a um número cada vez maior de utentes e de melhorar a qualidade dos serviços prestados em todos os níveis e tipos de ensino. Portanto, pretendia-se massificar o acesso da população à educação e fornecimento de uma educação com uma qualidade aceitável, isto é, uma educação com um conteúdo apropriado e um processo de ensino-aprendizagem que promovesse a evolução contínua dos conhecimentos, habilidades, atitudes e valores, de modo a satisfazer os anseios da sociedade (MEC, 1995, p. 15).

Como forma de concretizar o sonho, o Ministério da Educação e Cultura (MEC) objetivava "Formar o professor como educador e profissional consciente com profunda preparação científica e pedagógica, capaz de educar os jovens e adultos" para tal, segundo aponta o MEC (1995) a formação inicial e o aperfeiçoamento contínuo dos professores constituem um núcleo de atividades estratégicas para a melhoria da qualidade do ensino.

À semelhança dos vários problemas que apoquentam a sociedade nesse período pós-guerra civil (1992), a problemática da melhoria da qualidade de ensino/educação escolar em Moçambique também liderou as manchetes de vários órgãos de informação tendo alcançado os pacatos cidadão leigos inclusive em ambientes de café, de transporte até mesmo de velório. Dados do último Censo populacional do Instituto Nacional de Estatística (INE, 2017) apontam para cerca de 28 milhões de habitantes e com alto índice de analfabetismo, fato que pouco se distancia da realidade identificada nos primeiros anos da independência nacional onde a taxa de analfabetismo no país cifrava os 93 por cento, isto é, apenas sete em cada 100 moçambicanos (jovens e adultos) sabiam ler e escrever, embora atualmente a situação tenha mudado, fixando-se a taxa de analfabetismo em cerca dos 44,9 por cento, ou seja, em cada 100 jovens e adultos 55 sabem ler e escrever $\left(\mathrm{AIM}^{9}, 2016\right)$.

Isto equivale dizer que cerca da metade da população é analfabeta e uma vez mais chama-se ao apelo do trabalho do sistema educativo para a inversão do atual

9 Agência de Informação de Moçambique. Acesso em 08.09.2018, disponível no sítio: http://www.dw.com

Revista Vozes dos Vales - UFVJM - MG - Brasil - № 20 - Ano X - 10/2021 Reg.: 120.2.095-2011 - UFVJM - QUALIS/CAPES - LATINDEX - ISSN: 2238-6424 - www.ufvjm.edu.br/vozes 
quadro. Com efeito, o Ministério da Educação e desenvolvimento humano (MINEDH) tem estado a desenvolver esforços perspectivando reduzir os índices de analfabetismo através da priorização da expansão da rede escolar e a formação de professores (MINEDH, 2013,p. 46. e 2017,p.13). Porém, dada a emergência em reabastecer a rede escolar e garantir que as escolas tenham professores formados, sucede a projeção de modelos de formação em cascata como descreve MEC (2011,p. 10) sendo um deles o modelo da $7^{\mathrm{a}}+2+1$ ano, que comporta 2 anos de formação e um de estágio profissional, o que garantia com que no ano de estágio cada formando responsabilizava-se por uma turma mediante a celebração de um contrato laboral efectivo. Registrou-se igualmente, a existência do Modelo da $10^{\mathrm{a}}+2$ anos que foi basicamente pedagógico constituído por metodologias específicas para a docência no ensino primário e disciplinas das ciências da educação e práticas de ensino integradas; $\quad O$ Modelo da $10^{\mathrm{a}}+1+1$ que funcionou como variante do modelo da $10^{\mathrm{a}}+2$, tendo emergido da necessidade de se formar mais professores para o ensino primário em curto espaço de tempo à semelhança do modelo da $7^{\text {a }}$ +2+1; O Modelo da $10^{\mathrm{a}}+1 \mathrm{em}$ vigor atualmente que é o espelho de um modelo intensivo da preparação docente enquadrado em uma situação que visa responder os desafios de desenvolvimento do Milénio.

Fato é que, em todos esses modelos de formação docente, o denominador comum é a primazia que se dá ao conhecimento pedagógico, e nesses últimos $\left(7^{\mathrm{a}}\right.$ $+2+1$ e $\left.10^{\text {a }}+1\right)$ com agregação do conhecimento pedagógico sobre o objeto de ensino (PCK em Shulman, 1987), preterindo-se o conhecimento sobre objeto do ensino, Conhecimento curricular, Conhecimento das características dos aspectos cognitivos e da motivação dos estudantes, conhecimento do contexto educativo e conhecimento das finalidades educativas dos valores educativos e dos abjetivos.

Em uma visão sistêmica como refere Senge (1990) todas as interfaces do sistema como são os casos das componentes do conhecimento profissional (GARCIA, 1999) devem estar integradas, articulados e corroborativos de modo a alcançar-se os melhores resultados. E, conforme categoriza os modelos de formação Altet (2000), os modelos de formação em alusão enquadram-se na segunda categoria sendo modelos de formação em que o móbil é a aquisição e

Revista Vozes dos Vales - UFVJM - MG - Brasil - № 20 - Ano X - 10/2021 Reg.: 120.2.095-2011 - UFVJM - QUALIS/CAPES - LATINDEX - ISSN: 2238-6424 - www.ufvjm.edu.br/vozes 
aplicação de saberes, o que equivale dizer que o egresso dessa formação será como um "artista" que poderá transmitir o saber-fazer usando truques e, outra particularidade é que o docente formador nesses modelos de preparação docente é na maioria das vezes um indivíduo experiente e modelo e não um profissional qualificado para o efeito.

Em se tratando de um país com maior índice de analfabetismo e predominância de uma maioria populacional não falante da língua portuguesa, a língua oficial de ensino, entendemos que o modelo integrado de formação baseado na análise, reflexão na ação, resolução de problemas, prática-teoria-prática, é o que melhor se ajustaria para uma adequada formação inicial docente, considerando que o modelo integrado de formação baseado na prática reflexiva do Profissional, projeta no futuro profissional o desenvolvimento de saberes arraigado nas investigações indutivas e dedutivas específicas da ação docente (SCHON, 1987; GARCIA, 1999; ALTET, 2000; IMBERNÓN, 2011).

Reconhecendo o enfoque atual sobre a necessidade da transformação da escola e do ensino (GARCIA, 1999; SACRISTÁN e GÓMEZ, 1999), preparar novos professores para dinamizar um ensino questionador (IMBERNÓN, 2011 e DARLINGHAMMOND e BRANSFORD, 2019), tornou-se desafiador e compromissante, daí que afirmamos parafraseando Altet (2000) que os tempos atuais não mais são de carisma e dom, tão pouco da racionalidade técnica na preparação docente, tornando-se fundamental e urgente repensar-se em uma formação docente que atenda às especificidades modernas do ensino, que na ótica de Sacristán e Gómez (1999, p.70), deve ser considerado como um processo que facilita a transformação dos alunos. Nesse aspecto, entendemos que o eixo condutor para uma formação docente qualificada passa necessariamente pela implantação e desenvolvimento de ações institucionais sistêmicas em contraposição à negligência dos tendões de relacionamento entre os diversos apoiadores (MARTUCCELLI, 2007).

O historial da trajetória da formação docente em Moçambique, revela-nos existência de desvio no processo de formação de professores dada a implementação de vários modelos de curta duração e não consolidados, sem uma

Revista Vozes dos Vales - UFVJM - MG - Brasil - № 20 - Ano X - 10/2021 Reg.: 120.2.095-2011 - UFVJM - QUALIS/CAPES - LATINDEX - ISSN: 2238-6424 - www.ufvjm.edu.br/vozes 
integração da formação contínua baseada na prática do ensino-aprendizagem. Trata-se de modelos de formação docente que pouco possibilitam uma preparação do professor como sujeito ou indivíduo cultural capaz de dinamizar um processo de ensino-aprendizagem arraigado em valores culturais. Na acepção da formação do indivíduo Martuccelli (2007, p.62) advoga que não é, portanto, a constituição do indivíduo que está em questão, mas dos procedimentos pelos quais ele se coloca diante do mundo. E esses meios não são diferentes do conjunto de elementos, materiais e imateriais, que o ligam ao seu contexto. A estabilidade do indivíduo não deve ser encontrada nem em sua interioridade nem em seu trabalho narrativo. A vontade e a ação individual recebem um importante valor agregado em função dos suportes que as cercam. O indivíduo não se esconde atrás desses círculos e dessas estruturas. Não é, portanto, inteiramente exterior a si mesmo, embora, evidentemente, não consiga, de forma alguma, conceber-se como capaz de se estruturar a partir de sua própria intimidade. Portanto, os investimentos institucionais para a formação docente (infraestruturas, currículo, materiais didáticos, formadores qualificados, entre outros), devem estar em altura de gerar mudanças no sujeito da formação, para que este projete mudanças necessárias no seu contexto.

Ao longo do processo histórico da formação de professores/as para o ensino primário em Moçambique a dimensão do indivíduo no que concerne à construção de suportes para uma individuação própria do papel social do professor apresentou-se negligenciada conforme as análises descritivas acima e tendo-se procurado formar uma "máquina humana" para transformar os objetivos do Sistema Nacional de Educação (SNE) com o mínimo de conhecimentos profissionais e sem condições estruturais.

Pelos dias que correm regista-se mais de quatrocentos mil alunos (crianças do ensino primário entre 6-12 anos de idade) estudando por baixo de sobras de árvores totalizando cerca de oito mil turmas no relento segundo dados do Ministério da Educação e Desenvolvimento Humano (MINEDH, 2016). A questão de fundo que se levanta é: será que o professor foi preparado para corresponder o nível da precaridade da escola como se apresenta? A resposta é óbvia tomando como base os resultados escolares publicados no anuário de estatística educacional de 2017 , a

Revista Vozes dos Vales - UFVJM - MG - Brasil - № 20 - Ano X - 10/2021 Reg.: 120.2.095-2011 - UFVJM - QUALIS/CAPES - LATINDEX - ISSN: 2238-6424 - www.ufvjm.edu.br/vozes 
percentagem é de cerca de $76 \%$ de alunos aprovados (MINEDH, 2017) todavia, na generalidade as crianças apresentam deficit do domínio da oralidade e escrita na língua portuguesa e na aritmética básica, sendo problemas graves do ensino identificados já em vários estudos (GOLIAS, 1991 e GOMÉZ, 2010).

Embora a problemática da aprendizagem seja conjuntural e sistêmico em Moçambique segundo diagnósticos do Ministério da Educação (MINED, 1998;2004; 2012; MEC, 2006; MINEDH, 2020), é ao professor que se lhe imputa profissional e socialmente a responsabilidade pelo fracasso e insucesso escolar na maioria das vezes, sendo que desde a sua formação até ao exercício da docência não encontra suportes que o sustentam para o enfrentamento das adversidades sistêmicas da problemática escolar. Na compreensão do Ministério da Educação moçambicana, formar o professor como educador e profissional consciente com profunda preparação científica, pedagógica, ética, moral capaz de educar a criança, o jovem e o adulto com valores da moçambicanidade (MINEDH, 2020, p.41), todavia não se acham presentes tanto no sistema de educação e formação docente assim como nos sujeitos de formação, os suportes necessários para a eficácia da preparação docente e para o exercício profissional.

Os suportes referem-se aos aportes da tecnosfera ${ }^{10}$ e psicoesfera ${ }^{11}$ que impactam na realização e transformação de uma certa realidade. Nesse diapasão, Martuccelli (2007) defenda que "o número de suportes não diz nada sobre sua qualidade" todavia,

Si el uno no compensa siempre al outro, es absolutamente a veces el caso. Lo importante, es la manera como los individuos constituyen sustentáculos por el medio indirecto de relaciones o de objetos, que se cargan, entonces, de nuevos significados, más aqui o má allá de los roles tradicionales. Incorporados a pesar de la distancia o bien, al contrario, pese a la proximidade, crean alrededor de cada uno de nosotros un tejido elástico compuesto de relaciones profesionales, amistosas, familiares, o de conocimientos. Esse es nuestro verdadero mundo. Es éste el que es proteiforme, y no el individo, incluso si él no se tiene sino gracias a aquél, (MARTUCCELLI, 2007, pp. 60-61).

\footnotetext{
${ }^{10} \mathrm{~A}$ tecnoesfera refere-se ao mundo dos objetos.

${ }^{11}$ A psicoesfera refere-se ao mundo das ações. Os objetos artificiais, são híbridos, já que não têm existência real, valorativa, sem as ações (SANTOS, 2014, p. 159).

Revista Vozes dos Vales - UFVJM - MG - Brasil - № 20 - Ano X - 10/2021 Reg.: 120.2.095-2011 - UFVJM - QUALIS/CAPES - LATINDEX - ISSN: 2238-6424 - www.ufvjm.edu.br/vozes
} 
Portanto, a construção de uma amálgama entre a tecnoesfera e a psicoesfera no subsistema de educação e formação docente em Moçambique, configura-se como um suporte indiscutível para o melhoramento da educação. Contudo, é de encorajar que as políticas públicas destinadas ao sector da educação sejam transformadas em ações proeminentes no desenvolvimento de uma educação de qualidade.

\section{Conclusões}

Nesta reflexão procuramos analisar a dimensão do suporte na formação de professores primários em Moçambique nos períodos de transição de formaçao de professores (1975-1976), período de consolidação na formação de professores para o SNE (1977-1991) e o período de reforma do SNE e de reconstituição da rede escolar (1992 ao presente momento).

Conclui-se que no primeiro período a intenção foi de implantar a introdução de um sistema educativo moçambicano sem contudo ter-se planificado os aportes necessários para a formação docente pois nesse período o país não detinha de profissionais para dar face ao projeto de formação. Daí resultou que o partido governante do Estado, transformou a formação docente em célula do partido onde preparava-se ideologicamente os futuros professores para transmitir a visão ideológica partidária do Estado monopartidário.

No segundo período além de se ter criado o SNE, implantou-se o subsistema de formação docente contudo, os programas de formação registraram melhorias pois nos modelos de $6^{a}$ e $7^{a}$ classes mais três anos de formação além do conhecimento pedagógico, passou a atender-se ao conhecimento de conteúdo, que consideramos como sendo um suporte científico fundamental para a docência.

No período de reforma do SNE e de reconstituição da rede escolar que inicia em 1992 ao presente momento, os modelos de formação pouco evoluíram no que conserne aos saberes necessários para a docência, a não ser apenas o nível de entrada na formação que foi elevada da $7^{\mathrm{a}}$ para a $10^{\mathrm{a}}$ classe.

Revista Vozes dos Vales - UFVJM - MG - Brasil - № 20 - Ano X - 10/2021 Reg.: 120.2.095-2011 - UFVJM - QUALIS/CAPES - LATINDEX - ISSN: 2238-6424 - www.ufvjm.edu.br/vozes 
Em todo esses períodos históricos da formação de professores em Moçambique foram atendidas duas das sete categorias de base de conhecimento para a formação docente (SHULMAN, 1987) o que comprova a ideia de ausência de sustenes para a criação de uma amálgama profissional consistente no futuro professor.

\section{Referências}

ALTET, Marguerite, Análise das práticas dos professores e das situações pedagógicas. Porto, Porto Editora, 2000

Arroyo, Miguel G. Ofício de mestre: imagens e autoimagens, $15^{\mathrm{a}}$.ed. Petrópolis, RJ: Vozes, 2017

Brück, Tilman, Guerra e desenvolvimento em Moçambique. Análise Social, vol. xxxiii (149), 1998 (5 o), 1019-1051

DARLING - HAMMOND, Linda e BRANSFORD, John. Preparando os professores para um mundo em transformação: o que devem aprender e estar aptos a fazer. Porto Alegre: Penso, 2019

Diniz- Pereira. J.E. Da Racionalidade Técnica À Racionalidade Crítica: Formação Docente E Transformação Social. Perspec. Dial.: Rev. Educ. Soc., Naviraí, v.01, n.01, p. 34-42, jan-jun.2014: Home-page: http://www.seer.ufms.br/index.php/persdia

FRANCO, Maria Amélia Santoro. Formação Continuada De/Para/Com Docentes: Para Quê? Para Quem? In: IMBERNÓN, Francisco, NETO, Alexandre Shigunov e FORTUNATO, Ivan (org.): Formação Permanente De Professores: Experiências Iberoamericanas. São Paulo: Edições Hipótese, 2019. 554p.

Freire, Paulo. Pedagogia da autonomia: Saberes necessários prática educativa. $55^{\mathrm{a}}$ ed. RJ/SP: Paz e Terra, 2017 . Pedagogia do oprimido, $65^{\mathrm{a}}$.ed. RJ/SP: Paz e Terra, 2018

GATTI, B.A. Formação de professores: condições e problemas atuais. Revista Internacional de Formação de Professores (RIPF). Itapetininga, v. 1, n.2, p. 161-171, 2016 (Artigo publicado na Revista Brasileira de Formação de Professores - RBFP - ISSN 1984-5332 -Vol. 1, n. 1, p.90-102, Maio/2009)

Revista Vozes dos Vales - UFVJM - MG - Brasil - № 20 - Ano X - 10/2021 Reg.: 120.2.095-2011 - UFVJM - QUALIS/CAPES - LATINDEX - ISSN: 2238-6424 - www.ufvjm.edu.br/vozes 
GARCIA, Carlos M. Formação de professores: para uma mudança educativa. Porto, Porto Editora, 1999.

Golias, Manuel. Formação de professores primários: Balanço e perspetivas. Maputo, 1991

- Sistemas de Ensino em Moçambique: passado e presente. Maputo. Editora escolar, 1993.

. Educação Básica: Temáticas e Conceitos. Maputo. Editora escolar; Maputo; 1999.

GÓMEZ, Miguel Buendía. Educação moçambicana: história de um processo, 1962-1984, Maputo, Moçambique: Livraria Universitária, Universidade Eduardo Mondlane, 1999.

IMBERNÓN, Francisco. Formação docente e profissional: formar-se para a mudança e a incerteza, 9a . Ed. São Paulo, Cortez, 2011

INDE. Plano de estudos do curso de formação de professores do primeiro grau do ensino básico. Maputo, 1998

MARTINS, flávia e NHAMPULE, Ana Maria. Uma breve Reflexão sobre o perfil linguístico do professor do EP1. Maputo, INDE, 1997

MARTUCCELLI, Danilo. Gramáticas del individuo. $1^{\text {a }}$ ed. Buenos Aires: Losada, 2007

Mazula, B. (1995). Educação, Cultura e Ideologia em Moçambique: 19751985. Portugal, Porto: Edições Afrontamento A Educação Colonial de 1930 a 1974. Disponível em: http://www.macua.org/livros/Aeducacaocolonialde1930a 1974.htm. 12/07/2017 10

MEC. Trajectória sobre o sistema de formação de professores em moçambique. Maputo, 2011

MEC. Política Nacional de Educação e Estratégia de Implementação. Maputo, Resolução nº 8/95 de 22 de Agosto de 1995

MEC. Plano Estratégico da Educação e Cultura: Fazer da escola um polo de desenvolvimento consolidando a Moçambicanidade. Maputo, 2006

MINED. Estratégia para a Formação de Professores 2004 - 2015, Proposta de Políticas. Maputo: Ministério da Educação, 2004

MINED. Plano Estratégico da Educação 2012 - 2016: "Vamos aprender!" Construindo competências para um Moçambique em constante desenvolvimento. Maputo: Ministério da Educação, 2012.

Revista Vozes dos Vales - UFVJM - MG - Brasil - № 20 - Ano X - 10/2021 Reg.: 120.2.095-2011 - UFVJM - QUALIS/CAPES - LATINDEX - ISSN: 2238-6424 - www.ufvjm.edu.br/vozes 
NÓVOA, António. Formação de professores e profissão docente. In: (Org.). Os Professores e a sua Formação. Lisboa: Nova Enciclopédia, Publicações Dom Quixote, 1995.

NÓVOA, António. Professores Imagens do futuro presente. Lisboa: Educa, 2009

SANTOS, Amilton, 1926-2001. O espaço do cidadão. 7.ed., Editora da Universidade de são Paulo, 2014.

SENGE, Peter M. A quinta disciplina - Arte Teoria e Prática da Organização de Aprendizagem. São Paulo: Editora Best Seller, 1990

Shulman, L. (1987). Conhecimento e ensino: fundamentos da nova reforma. Harvard Educational Review, 57 (1), 1-22

AIM. 2016. $\quad$ Http://www.dw.com/pt-002/em-mo \%c3\%a7ambique-quase-metade-da-popula\%c3\%a7\%c3\%a3o\%c3\%a9-analfabeta/a-19529655

Processo de Avaliação por Pares: (Blind Review - Análise do Texto Anônimo)

Publicado na Revista Vozes dos Vales - www.ufvjm.edu.br/vozes em: 10/2021

Revista Cientifica Vozes dos Vales - UFVJM - Minas Gerais - Brasil www.ufvjm.edu.br/vozes

UFVJM: 120.2.095-2011 - QUALIS/CAPES - LATINDEX: 22524 - ISSN: 2238-6424

Revista Vozes dos Vales - UFVJM - MG - Brasil - № 20 - Ano X - 10/2021 Reg.: 120.2.095-2011 - UFVJM - QUALIS/CAPES - LATINDEX - ISSN: 2238-6424 - www.ufvjm.edu.br/vozes 